\title{
A syntactic analysis of the subject clitic $a$ in the Friulian variety of Campone
}

\author{
Jan Casalicchio \\ Università di Trento \\ jan.casalicchio@unitn.ti \\ Vania Masutti \\ Università di Padova \\ vania.masutti@studenti.unipd.it
}

Received: 03-03-15

Accepted: 03-06-15

\section{Abstract}

This article presents a syntactic analysis of the third person subject clitic $a$ in Camponese, a heretofore unstudied Friulian variety. Following Poletto's (2000) map of subject clitics, we argue that it bears [+third person] features, and is, in fact, the spellout of the functional head $\mathrm{Subj}^{\circ}$, located in the highest projection of TP (following Rizzi \& Shlonsky 2007).

In the first part of the article, we offer a detailed description of the distribution and syntactic properties of the subject clitic $a$, identifying its position in relation to the other elements that occur in the CP and TP. In the second part we discuss two proposals put forward to account for split clitics like $a-l$ in the related variety of Forni di Sotto, where $a$ and $l$ are held to be part of a single clitic al (Manzini \& Savoia 2009, Calabrese \& Pescarini 2014). We show that such an account is incompatible with the case of Campone, where the clitics $a$ and $l$ are clearly separate: $l$ is a [u $\varphi$ ]-clitic (Roberts 2010) and is located lower in the TP than the clitic $a$. We conclude with an analysis, which proposes the integration of Poletto's (2000) typology with a fifth type, corresponding to the clitic $a$ of Campone.

Keywords: Northern Italian Dialects; Friulian; subject clitics; Split CP; split subject features. 


\section{Table of Contents}

\author{
1. Introduction \\ 2. General description of \\ the subject clitic $a$ \\ in the variety of Campone \\ 3. Previous analyses of Friulian \\ subject clitics
}

\author{
4. The syntactic distribution of the \\ clitic $a$ in the structure \\ 5. Analysis of the subject \\ clitic $a$ in Campone \\ 6. Conclusions \\ References
}

\section{Introduction}

The Friulian variety of Campone is currently spoken by approximately 200 people in Campone (PN) and other Italian and European cities to which the inhabitants of Campone have emigrated over the years. ${ }^{1}$ Fifteen speakers permanently live in Campone, a small village in the Carnic Prealps. Our research investigates the syntactic properties of the subject clitics ('SCLs') in this variety, and, particularly, the syntactic distribution and function of the third-person subject clitics, focusing on the syntactic behaviour of the clitic a, which we instantiate in (1):
a. A nevea
$a$ snows
b. $\quad$ Mario a 1 scrif ${ }^{2}$
Mario a SCL write
'Mario is writing'

Several studies have been done of subject clitics in Northern Italian Dialects (NIDs), starting with Brandi \& Cordin (1981) and Renzi \& Vanelli (1983). The question of the syntactic properties of subject clitics in NIDs is particularly relevant since they interact with other crucial parameters, such as pro-

This article is based on the paper we presented at CIDSM8 in Padua. We would like to thank an anonymous reviewer and our audience in Padua for useful comments and remarks and Rachel Murphy for reviewing the English of the article. The article is a joint work; however, for the concerns of the Italian Academy Vania Masutti takes responsibility for $\S \S 1,2$ and 4, and Jan Casalicchio for $\S \S 3,5$ and 6 . This work was supported in part by the European Union's Seventh Framework Programme for research, technological development and demonstration, grant no. 613465 (project AThEME - Advancing the European Multilingual Experience)

2 For the examples in Camponese we use a simplified non-phonetic transcription, based on the Italian spelling norms. The duration of the vowels is not indicated, since it is not relevant for the present analysis and since the vowel length in this variety generally conforms to the system of western Friulian, where it has no phonological status (Frau 1984). As regards the glosses, we leave the clitic $a$ unglossed, while we use 'SCL' for the lower subject clitics $l / \phi / i / s$. 
drop, as has been noted since Brandi \& Cordin $(1981,1989)$. $^{3}$ The interaction between the pro-drop parameter and the cliticisation of pronominal subjects gives us interesting pointers for the study of the developmental cline of subject pronouns in diachrony (Vanelli 1987, 1998; Benincà, Renzi \& Vanelli 2007). Poletto (2000) and Manzini \& Savoia (2005) provide a particularly interesting overview of subject clitics in synchrony in NIDs.

Our investigation mainly concentrates on the synchronic properties of subject clitics. Taking the analyses of Brandi \& Cordin and Poletto as our starting point, we provide new data from the variety of Campone, which adds to the picture that has emerged from previous studies. The data were collected through a questionnaire completed by native speakers of Camponese, and by one native speaker from Forni di Sotto, to provide a comparison. We compare the syntactic properties of the subject clitic $a$ with those of the same clitic in other typologically and geographically close varieties, considering in particular the dialect of Forni di Sotto (PN), analysed in Manzini \& Savoia (2009) and Calabrese \& Pescarini (2014).

The article is organised as follows: section 2 is a general overview of subject clitics in the variety of Campone, in which the paradigm and the contexts of use of the clitic $a$ are discussed. In section 3 we examine previous accounts of subject clitics, such as Poletto's (2000) typology of subject clitics in NIDs, and Manzini \& Savoia (2009) and Calabrese \& Pescarini (2014)'s studies of the varieties of Forni di Sotto. In line with cartographic analyses, in section 4 we use some syntactic tests to determine, as far as possible, the target position of the clitic a in the syntactic structure. In section 5 we propose our analysis for the clitic a in Camponese, basing it on a comparison with previous accounts. The last section presents our conclusions.

\section{General description of the subject clitic $a$ in the variety of Campone}

\subsection{Verb paradigm and clitic series}

As in many NIDs, the variety of Campone displays two series of subject pronouns, one clitic, the other strong. Our analysis concentrates on the clitic series, specifically on the subject clitics encoding the third person feature. We will thus investigate the syntactic properties of the third person subject clitic, which appears to include two independent morphemes, forming a clitic cluster: the higher (fixed) component of the cluster is the clitic $a$, which co-occurs with a lower (variable) clitic which has distinct outcomes for gender and number. The clitic $a$ is found in all third person contexts, which can be both referential and non-referential.

Before examining this subject clitic in detail, we will briefly provide an overview of the clitic paradigm in the variety of Campone. The proclitic series of subject pronouns is incomplete: clitics only exist for the second and third person singular and for the third person plural. Note that no subject clitic exists for the

3 The pro-drop parameter has been widely analysed in the literature from the 1980's on (see Rizzi 1982 for Italian), and still is (for a Minimalist account on pro-drop and cliticisation see Holmberg \& Roberts 2010 and Roberts 2010). 
first person singular or plural, or for the second person plural, whereas several Friulian varieties use the clitic $o$ (central Friulian) or $i$ (western Friulian) for these persons. ${ }^{4}$ The paradigm of subject clitics for the variety of Campone thus conforms to the third generalisation given in Renzi \& Vanelli (1983): if a variety has regular recourse to (at least) three subject pronouns, the forms used are those for the second, third and sixth person. Within Roberts' (2010: 106) classification of null-subject languages, the variety of Campone largely corresponds to a nonredundant null-subject systems, namely the "type c" (SCL[-agr] V[+agr]) of Roberts' classification. The example 0 shows the paradigm of subject proclitics and verb inflections for the verb fevelà (to speak): ${ }^{5}$

$\begin{array}{ll}\varnothing & \text { fevel-i } \\ \text { tu } & \text { fevel-a } \\ \text { a 1 / a } \emptyset^{6} & \text { fevel-a } \\ \varnothing & \text { fevel-àn } \\ \varnothing & \text { fevel-àis } \\ \text { a i / a s } & \text { fevèl-an }\end{array}$

The enclitic series is complete in Camponese, without gaps or cases of syncretism (SCL [+agr]), as noted in Poletto (2000) for other Friulian varieties. This is exemplified in 0 for the verb chiantà - 'to sing' (given in the present tense):
a. chiànt-jo?
b. chiànt-i-tu?
c. chiànt-al? / chiànt-a?
d. chiantà-no?
e. chiantà-vo?
f. chiànt-ai / chiànt-as?
'Do I sing?', etc.

To sum up, the paradigm for the proclitic and enclitic series of subject pronouns is repeated in Table 1:

$4 \quad$ The subject clitic $i$ for the first person singular is found, for instance, in the Friulian variety of San Michele al Tagliamento (Benincà 1994b). More precisely, this $i$ - analysed by Poletto (2000) as a deictic clitic - is used for the first and second persons singular and plural: it is thus insensitive to singular versus plural distinctions, but encodes the [+/-third person] feature.

$5 \quad$ We indicate the third person clitics $a l, a i$, and $a s$ as two separate words: as we will show later, these forms are not a single clitic, but a cluster of two separate subject clitics.

6 We envisage the presence of a lower clitic $\varnothing$ for the feminine singular on the basis of the analogy with the other third persons. The referential subject clitic for the feminine singular is thus treated as $a+\phi$, and must not be confused with the expletive $a$, used in non-referential contexts. We therefore do not think that the form of the feminine singular corresponds to the expletive, as it does in other dialects - e.g. the Provencal variety of Rorà described in Benincà (2011) - where the etymological feminine has the role of expletive subject. 


\begin{tabular}{|c|c|c|c|c|}
\hline Person & \multicolumn{2}{|c|}{ Singular (M/F) } & \multicolumn{2}{|c|}{ Plural (M/F) } \\
\hline 1. & \multicolumn{2}{|l|}{$-/$-jo } & \multicolumn{2}{|l|}{$-/$-no } \\
\hline 2. & \multicolumn{2}{|l|}{ tu / - tu } & \multicolumn{2}{|l|}{ - / -vo } \\
\hline 3. & a $1 /$-al & $\mathrm{a} \varnothing /-\mathrm{a}$ & a i / -ai & a s / -as \\
\hline
\end{tabular}

Table 1: Proclitic and enclitic series of referential subject pronouns in Camponese

\subsection{The contexts of use of the SCL a}

Table 1 shows that the clitic $a$ exclusively refers to the third person, for both singular and plural subjects. In referential contexts, the clitic $a$ co-occurs with a second clitic, which is $-l$ for the masculine singular, $\varnothing$ for the feminine singular, $-i$ for the masculine plural and $-s$ for the feminine plural. The contexts in which the clitic cluster is found are exclusively referential, i.e. we obtain a referential reading when $a$ is accompanied by a lower clitic-.

This cluster mandatorily doubles any type of definite subjects, both when they are in pre-verbal (4) and post-verbal position; in the latter case, the cluster is mandatory both with unergative and unaccusative verbs, see (5):
a. Mario a 1 ha manghiat e a 1 è giut in tal liet
Mario $a$ SCL has eaten and $a$ SCL is gone in to.the bed
'Mario ate and went to bed'
b. Lui a 1 ha un riftiel nouf
$\mathrm{he}_{\text {strong }} a \mathrm{SCL}$ has a rake new
'He has a new rake'

(5)
a. A s han clamat las agnas
$a$ SCL have called the aunts
'The aunts called'
b. A 1 è vignut Mario
$a$ SCL is come Mario
'Mario has come'
c. A i son rivaz i tiè fradis
$a$ SCL are arrived the your brothers
'Your brothers arrived'

The clitic cluster also doubles indefinite subjects, as its co-occurrence with the indefinite quantifiers in (7) shows. This fact is relevant in that it demonstrates that the doubling does not necessarily involve left-dislocated subjects:

(6) a. Duch a i crout chi lui a 1 seipi siò fi

everybody $a$ SLC believe that he $a$ SLC is his son

'Everybody thinks he is his son'

b. Nisun a 1 è giut in tà l'osteria ier

nobody $a$ SLC is gone in to.the pub yesterday

'Nobody went to the pub yesterday' 
Moreover, the clitic cluster doubles a pronominal wh-, both in enclitic and proclitic position:
a. Cui ven-al?
who come-al
b. Cui ch'a l ven?
who that $a$ SLC comes
c. Cu ch'a lè ch'a 1 ven?
who that $a$ SLC is that $a$ SLC comes
'Who is coming?'

Finally, relative pronouns with both a restrictive (8a-b) and an appositive $(8 \mathrm{c})$ reading co-occur with the clitic cluster, too: ${ }^{7}$

(8) a. Las canajas ch'a s claman dutas las seras a s son las sos amigas the girls that $a$ SLC call all the evenings $a$ SCL are the their friends 'The girls who call every evening are her friends'

b. Atu vidut i canais ch'a i son rivaz ier?

Have.you seen the boys that $a$ SCL are arrived yesterday

'Have you seen the boys who arrived yesterday?'

c. Hai vidut la Luisa, ch'a no $\varnothing$ ha cjapat soreli chest'an

I.have seen the Luisa, that $a$ not $\operatorname{SCL}(\varnothing)$ has taken sun this year

'I saw Luisa, who has not tanned this year'

Whereas in referential contexts $a$ forms a cluster with a lower clitic, the clitic $a$ alone occurs in non-referential contexts, both in proclisis and in enclisis. This is particularly the case of semi-argumental verbs ${ }^{8}$ :
a. A nevea
$a$ snows
'It snows'
b. A plouf
$a$ rains
'It rains'
c. Plov-a?
rain- $a$

'Does it rain?'

$\overline{7} \quad$ Note that sentences like (8) are only apparent counterexamples to Rizzi's (1986) approach to relative clauses: the cluster $a i$ (instead of $a$ alone) appears independently of the position from where the subject moves, because in Campone these clusters appear with any definite subject. Thus, it is possible to maintain that the subject of unaccusative verbs moves from a post-verbal position, as in Rizzi's analysis (we thank an anonymous reviewer for suggesting us this comparison).

8 In central Friulian, instead, $a l$ is used also with semiargumental verbs (see also Vanelli 1998: 108):
(i)
$\begin{array}{ll}\text { a. } & \text { Al plûf } \\ \text { b. } & \text { Plovial? }\end{array}$
(Tricesimo and Baldasseria, Udine) 
Furthermore, the clitic $a$ alone is used in unaccusative constructions, when the subject is indefinite and post-verbal. This is the case of the impersonal/mediopassive si (10) and passives with an unexpressed agent (11):

(10) A si vomp mà tanch cervos a pasà in chel prat

$a$ REFL see a lot of deer to go.through in that meadow

'You can see a lot of deer passing through that meadow'

(11) A son staz spinduz mà tanch bez ${ }^{9}$

$a$ are been spent a lot of money

'A lot of money has been spent'

The same holds for contexts of free subject inversion with unaccusative verbs involving an indefinite subject (12) (cf. with (5), where the subject is postverbal but definite and fully identified): ${ }^{10}$
a. A son rivaz trei canais
$a$ are arrived three boys
'There arrived three boys'
b. A son rivaz duciu tarc
$a$ are arrived all late
'They arrived all late/ Everybody arrived late'

To sum up, the subject clitic $a$ is used in all contexts that include a third person, which may be both referential and non-referential. The only exception is the impersonal verb bisugna - 'it is necessary', which only marginally admits the clitic $a$. As pointed out in Benincà \& Poletto (1994), bisogna is the verb with the poorest thematic grid: ${ }^{11}$
(?a) bisugna cori
$a$ is.necessary.to run
'It is necessary to run'

This demonstrates that the clitic $a$ is in some way connected with both the third person features and the thematic grid of the verb.

$9 \quad$ Note that in the interrogative paradigm the enclitic $a$ is related to a lower clitic $l / i / s$ in passive contexts, too:

(i) Son-ai staz spinduz ma tanch bez? are-ai been spent all the money 'Has all the money been spent?'

10 In this respect, unaccusative verbs differ from unergatives, where the clitic cluster $a l$ is used also with indefinite post-verbal subjects:

(i) Ier a s han durmit trei canajas uchì yesterday $a$ SCL have slept three girls here

'Three girls slept here yesterday'

11 We thank an anonymous reviewer for pointing out this relationship. 


\subsection{Syntactic properties of the referential SCL in negative contexts}

The examples provided in the last paragraph show that the clitic $a$ occurs together with a lower clitic in referential contexts, so that the two clitics may be interpreted as a unique morpheme. However, negative contexts reveal the different derivation of the two parts included in the SCL: with proclitics, the negative clitic no must intervene between $a$ and the lower part of the clitic, as shown by the examples in (14) vs. (15):

(14) a. Giani a no l'ha studiat

John $a$ not SCL has studied

'John did not study'

b. A no i vif uchì

$a$ not SCL live here

'They $\mathrm{m}_{\mathrm{m}}$ do not live here'

c. Cui ch'a no l ven?

who that $a$ not SCL comes

'Who is not coming?'
a. *No a l'ha studiat
not $a$ SCL has studied
b. *A 1 no ha studiat
$a$ SCL not has studied

In negative questions with $\mathrm{V}$-to-C movement (16), instead, the negative clitic no is higher than the finite verb, whereas al is enclitic:

\section{(16) No scriv-al? \\ not write-al \\ 'Doesn't he write?'}

In this case, al could be analysed either as a verbal agreement marker ("interrogative inflection") or as the same cluster $a l$ that is used in proclisis. The first position implies that the enclitic verbal inflection is [+pronominal] and thus able to identify pro in the TP (see Cardinaletti 1990, Tomaselli 1990 for licensing and identifying pro under government); the second position implies that only the finite verb and the clitic negation raise to the $\mathrm{CP}$, leaving the subject clitic in its canonical position. We do not yet draw any conclusions about the nature of the referential clitic $a+l / \phi / i / s$ in enclitic position, ${ }^{12}$ only suggesting that the expletive

12 Notice that the status of the enclitics currently seems to be instable, and there is variation in the forms found in negative questions. Constructions like 0 can cooccur with other patterns attested in our corpus:
(i) a. No l partis-al?
b. No 1 partis-a?
not SCL leave- $a(l)$
'Isn't he leaving?'

The examples (ib), in particular, may corroborate the independence of the two parts of the clitic. 
$a$ used in non-referential contexts - in which the situation is clearer - is the same in proclisis and in enclisis.

As the examples discussed in this section show, in Campone the negation is the only element that appears (mandatorily) between the two subject clitics. In the varieties of central Friulian, instead, in negative contexts the clitic $a$ is omitted, and only the lower subject clitic appears: ${ }^{13}$
a. A l vjôt vs. Nol vjôt (Central Friulian; Vanelli 1998, 108) $a$ SCL see not.SCL see
'He sees' vs. 'He does not see'
John not SCL has called today
'John has not called today'
b. Zuan nol à telefonât intal dì di vuê (Baldasseria, UD)
c. No ti ha clamât usgnot not you has called this.evening
'He didn't call this evening'
(Tricesimo, UD)

Thus, the analysis of the variety of Campone is particulary revealing because it points more explicitly than the better studied central Friulian varieties to the syntactic properties of the clitic cluster $a+l / \phi / i / s$. In Camponese, the insertion of the negation between $a$ and the lower SCL suggests that the two clitics represent the overt/PF realization of different syntactic features (cf. infra).

Unlike in other western Friulian varieties, in Camponese the clitic negation is the only element which must intervene between the two parts of a SCL, and no other morphosyntactic material can occur between them. Neither pronominal 0a) nor lexical items $0 \mathrm{~b}$ ) can be interpolated between $a$ and the lower part of the subject clitic.
a. Lui a no 1 pos gì, si lour a s lu / *a lu s tormentan da sta a chiasa he $a$ not SCL can go, if they $a$ SCL him / $a$ him SCL bother to stay at home
'He cannot go out, if they keep on repeating him to stay at home'
b. $\quad *$ A ier l'ha clamat tiò fì $a$ yesterday SCL has called your son

In this respect, Camponese differs from the western Friulian variety of Forni di Sotto (PN), where not only the negation but also dative or accusative clitics can appear between the higher $a$ and the lower part of the subject clitic (see infra):
a. $\quad$ Mario a $\{1\}$ mi $\{1\}$ da chiste robe
(Forni di Sotto)
Mario $a$ (SCL) to.me (SCL) gives this thing
'Mario gives me this thing'

\footnotetext{
13 According to Vanelli (1998), the lower subject clitics appear only in the third person, while they are incompatible with the negation in the first and second person. Note that in 0 the lower subject clitic is not expressed because there is an object clitic (see infra for the same phenomenon in Forni di Sotto).
} 
b. Paolo a $\{1\}$ mi $\{1\}$ ha dit c'a no 1 mi clama insnut ${ }^{14}$

Paolo $a$ (SCL) to.me (SCL) has told that $a$ not SCL to.me call this

evening

'Paolo told me that he will not call me this evening'

The clitics in the varieties of Campone and Forni di Sotto display the same syntactic behaviour when the lower part of the subject clitic $(/ / \phi / i / s)$ occurs under the negation but above the other clitics. We thus suggest a tentative hierarchy of clitics for Camponese 0:

[ $a$ [ clitic negation $[\mathrm{l} / \phi / \mathrm{i} / \mathrm{s}$ [ accusative/dative clitics [ finite verb

Interestingly, the projection intended to host the clitic $a$ is higher than all the other clitics in both Campone and Forni di Sotto, while its position is unclear in central Friulian. $^{15}$

\section{Previous analyses of Friulian subject clitics:}

This section describes past analyses of subject clitics, focusing on those dealing with Friulian varieties and the subject clitic $a$. Benincà's (1994b) seminal account of subject clitics in the Friulian dialect of San Michele al Tagliamento has been followed by other analyses of the topic. We refer particularly to three works: Poletto (2000), an extensive study of the whole inventory of subject clitics in NIDs, and two studies of the dialect spoken in Forni di Sotto, which is closely related to Camponese: Manzini \& Savoia (2009) discuss the data of the clitic cluster $a+l / \phi / i / s$ within a more extensive examination of infixation and doubling phenomena in Romance varieties. Calabrese \& Pescarini (2014), on the other hand, argue for a general morphological - and not syntactic - explanation of cliticisation, and analyse the $a+l / \phi / i / s$ clitic cluster within this theory.

\subsection{Poletto's (2000) typology of subject clitics}

In her comprehensive work on subject clitics in NIDs, Poletto divides them into four different types, located in different projections within $\mathrm{CP}$ and $\mathrm{TP} .{ }^{16}$ The clitic

14 The corresponding Italian sentence, which the informant was asked to translate into her variety, was the following: "Paolo mi ha detto che non mi chiamerà stasera" ('Paolo told me that he won't call this evening'). Therefore, the subject clitic $l$ located under the dative $m i$ is arguably not a resumptive object pronoun. In the close western variety of Forni di Sopra (PN), instead, the clitic $a$ can occur under the negation together with the lower part of the subject clitic, as this example provided in Manzini \& Savoia (2005) show:
(i)
$\mathrm{N}-\mathrm{a}-\mathrm{l}$ duarm
not- $a$-SCL sleep
(Manzini \& Savoia 2005: 134)

However, in other varieties examined in Manzini \& Savoia (2005: 135), like Grizzo, $n a$ seems to be analysed as the form of the clitic negation. If $n a$ were used as a clitic negation itself, the subject clitic $a$ would be simply deleted before the negation, as in the central Friulian varieties. 
in the highest position in the $\mathrm{CP}$, always formed by a single vowel, is called "invariable clitic" by the author. Strictly speaking, this is not a true subject clitic, because it has the same form for all persons. Consequently, it does not bear any person or number feature, and the contexts in which it is used do not depend on syntax; instead, it has a pragmatic value. A good example of vocalic clitics is the clitic $a$ in the dialect of Padua, discussed in Benincà (1994a): the author observes that it is located in a higher projection within the $\mathrm{CP}$, since it precedes any subject pronoun (21) and is incompatible with filled Topic of Focus positions (22):

A no te parli mai

(Paduan)

$a$ not you talk never

'You never talk!'
a. $\quad *\{\mathrm{~A}\}$ chi $\{$ a $\}$ ze partio?
$a$ who is left
b. *Giorgio, a 'l parte doman (Adapted from Benincà 1994a, 20 f.) Giorgio $a$ SCL leaves tomorrow

According to Benincà, the pragmatic role carried by the clitic $a$ in Paduan consists in conveying emphasis or surprise. In Poletto's (2000) analysis, these invariable clitics move from the Focus position within $\mathrm{CP}$ to the Topic position, saturating both heads. Thus, they are incompatible with both left dislocated elements and $w h$-pronouns.

The second type of clitic is called "deictic clitic" by Poletto, and, like invariable clitics, it is formed by a vowel. It encodes the features [+/-deictic], ${ }^{17}$ since it has two forms: one for the first and second person, and one for the third person. Deictic clitics are used in many western Friulian varieties, like that of San Michele al Tagliamento (Benincà 1994b, Poletto 2000) and of Forni di Sotto (see infra). ${ }^{18}$ In these dialects, the clitic is $i$ for the first and second person (both singular and plural) and $a$ for the third persons: ${ }^{19}$

16 In her analysis, Poletto refers to "IP". In order to avoid confusion and to adopt a homogeneous terminology for all analyses, we will use "TP" when referring to her IP, except when we directly cite her structures.

The feature [+/-deictic] corresponds to a difference between the first and second person vs. the third person. In this article, we use instead the feature [+/-third person], because - as we will see infra - the clitic $a$ of Campone is not a deictic clitic in Poletto's sense. Moreover, the feature [+/-third person], which corresponds to Benincà \& Poletto's (2005) [+/-there] feature, seems to better suit the fact that the clitic $a$ is also used as an expletive pronoun. Note that in Calabrese \& Pescarini (2014) this same feature is referred to as [+/-participant]. For a distinction between a '+/-third person' node and a ' $\varphi$-features' node, which are usually encoded in a single clitic, see Harley \& Ritter (2002) (where the two nodes are called 'Participant' and 'Individuation') and Calabrese \& Pescarini (2014). Recall that in central Friulian, the deictic clitic $o$ is not used with the second person singular.

19 Note that deictic clitics can co-occur with lower subject clitics, as in (23) and (24). On the other hand, they are incompatible with invariable clitics. 


I mangi $\quad$ 'I eat, you eat, ...' $\quad$ (San Michele - Poletto 2000, 13)
I ti mangis
A 1 mangia $\quad$ etc.

I duarmi 'I sleep, you sleep, ...'(Forni di S. - Calabrese \& Pescarini 2014, 20)

I tu duars

A lduar etc.

These clitics are also located in $\mathrm{CP}$, as shown by the fact that they are higher than the verb when it moves to $\mathrm{C}$ in interrogative sentences: ${ }^{20}$
a. (I) mangi-tu un milus?
(San Michele - Poletto 2000, 69)
(I) eat-you an apple
'Are you eating an apple?'
b. A plof o a neve? (Forni di Sotto)
$a$ rains or $a$ snows
'Is it raining or is it snowing?'

Deictic clitics differ from the higher vocalic clitics because they do not encode pragmatic features, their use depending on syntactic factors alone. Moreover, deictic clitics are repeated in coordination (26), while vocalic clitics are not (27):
A nu plof e a nu neve
(Forni di Sotto)
$a$ not rains and $a$ not snows
'It is neither raining nor snowing'
A canto con ti e balo co lu
$a$ I.sing with you and I.dance with him
(Loreo (Veneto) - Poletto 2000, 24)
'I'm singing with you and dancing with him'

According to Poletto, the two remaining clitic types are located in TP. They also differ from the higher CP-clitics in their morphology: whereas the latter are just formed by a vowel, the TP-clitics are usually formed by a vowel and a consonant (except for the third plural masculine in some varieties). Poletto calls these two classes "number clitics" and "person clitics"; they are only realized in some persons: number clitics are realized for the third singular feminine and the third plural masculine and feminine, and they encode gender and number (28), while person clitics encode the feature [+/-hearer] and are realized only for the second singular and the third singular masculine (28): ${ }^{21}$

20 Note, incidentally, that the doubling of a lexical DP-subject through a deictic clitic (as in Forni di Sotto) is clear evidence of the fact that in these varieties the lexical subject always moves to a projection of the $\mathrm{CP}$ and cannot be in the ordinary subject position (Spec,TP) - otherwise it would be lower than the deictic clitic.

21 Since our analysis focuses on the higher clitic $a$, in this article we will refer to both the lower two clitic types as 'TP-clitics', without distinguishing them. 


$\begin{array}{llllllll}\text { TP-clitics: } & 1 & 2 & 3 \mathrm{f} & 4 & 5 & 6 \mathrm{~m} & 6 \mathrm{f} \\ \text { a. Number clitics } & - & - & 1+\mathrm{a} & - & - & (\mathrm{l})+\mathrm{i} & 1+\mathrm{e} \\ \text { b. Person clitics } & - & \mathrm{t}+\mathrm{V} & \mathrm{V}+\mathrm{l} & - & - & - & -\end{array}$

Poletto identifies a total of four main target projections for the different types of subject clitics, two located in the $\mathrm{CP}$, and two in the TP:

[LDP inv $\mathrm{SCL}_{\mathrm{j}}\left[\mathrm{CP}\right.$ deic SCL [FP $\mathrm{t}_{\mathrm{j}}\left[\mathrm{IP}\right.$ [NegP $_{\text {NumbP }} \mathrm{SCL}$ [HearerP SCL [SpeakerP inflV [TP]]]]]]]]] (Poletto 2000: 36)

Notice that the two major groups of clitics (CP-clitics and TP-clitics) are divided by NegP: in the varieties that realise negation preverbally (like the Friulian dialects), the negation appears higher than number and person clitics, and lower than CP-clitics. ${ }^{22}$ Identifying the role played by negation is thus an important step when distinguishing between the two main groups of clitics, and an important clue for our analysis of the clitic cluster $a+l / \phi / i / s$ in Campone. Keeping this in mind, we first turn to the two above mentioned analyses of the variety of Forni di Sotto, which is closely related to Campone.

\subsection{Manzini \& Savoia (2009) and Calabrese \& Pescarini (2014): two studies on Forni di Sotto}

Manzini \& Savoia (2009) deal with the clitic clusters $a+l$ and $a+s$ of Forni di Sotto within a more extensive analysis, which considers a number of phenomena found in Italian varieties that resemble the mesoclisis of some Spanish dialects. They argue against both morphological and phonological accounts previously postulated for the Spanish data. ${ }^{23}$ According to Manzini and Savoia, the particular value of a syntactic analysis is that it allows us to treat the Friulian order of clitics ( $a$ no l), the Spanish mesoclisis (Venda[lo]n instead of the standard Vendan[lo]) and other phenomena occurring in various Romance dialects (as parasitic plurals) similarly: all these unexpected orders or endings are interpreted as results of syntactic movement, rather than morphological metathesis.

As noted in $\S 2.3$, in the variety of Forni di Sotto more clitic elements intervene between the higher clitic $a$ and the lower $l / \phi / i / s$ : the clitic negation mandatorily occurs in this position, and the object clitic can optionally do so. In this respect, Forni is clearly different from Campone, where object clitics are always lower than the whole clitic cluster 0 . A further peculiarity of Forni is the possibility of doubling the lower subject clitic (30)-(31):

22 An alternative view is offered by Calabrese \& Pescarini (2014), which assume that subject clitics are always moved to a projection higher than negation, see infra.

23 The authors argue in particular against Halle \& Marantz's (1994) morphological account and Halle \& Harris's (2005) PF-based account of the Spanish mesoclisis. Manzini \& Savoia's analysis stems from previous work on data from Southern Italian and Arbëresh: they claimed that mesoclisis had to be analysed at the syntactic level (see e.g. Manzini \& Savoia 2007, 2008). 
(30) a (s) no s du'ar

(adapted from Manzini \& Savoia 2009: 21)

$a$ (SCL) not SCL sleep

'They $y_{\text {fem }}$ don't sleep'

(31) a $\{1\}$ mi $\{1\}$ dà chist (adapted from Calabrese \& Pescarini 2014: 277)

$a\{\mathrm{SCL}\}$ me $\{\mathrm{SCL}\}$ gives this

'He gives me that'

Manzini \& Savoia (2009), basing on the accounts put forward in Manzini $\&$ Savoia (2005) and Manzini (2008), observe that there is more than one position available for subject clitics: one higher than the negation, and one lower. ${ }^{24}$ The authors label these positions D: ${ }^{25}$

(32) $[\mathrm{D}$ a(s) $[$ no $[\mathrm{p}$ mi $[\mathrm{D} \mathrm{s} \quad$ [I du'ar

(adapted from Manzini \& Savoia 2009: 23)

Manzini and Savoia apparently analyse the forms $a l$, as and ai as a single clitic, and suggest that they are merged in the higher D position; from there, the lower part only is either copied or displaced into the lower D position.

Calabrese \& Pescarini (2014) interpret the split cluster $a+l / \phi / i / s$ within a morphological model of the cliticisation phenomenon. Following Halle-Marantz's (1993) Distributed Morphology theory, the authors claim that 'cliticisation' is the result of two different procedures: syntactic movement and morphological merge (m-merge); the latter brackets a functional head with an adjacent host (as in Marantz 1988). The authors, adopting an idea first proposed by Torrego (1992), assume that subject clitics are merged with the DP subject (which can also be a pro) in a big DP within Spec,vP. ${ }^{26}$ The entire big DP then moves to the subject position in Spec,TP; according to this account the subject clitic is not adjoined or incorporated to $\mathrm{T}^{\circ}$, as claimed in various analyses. ${ }^{27}$ Consequently, Calabrese and Pescarini claim that the 'link' between the subject clitic and the verb (i.e., the 'cliticisation') is not established in syntax, but in morphology: the clitic is mmerged to $\mathrm{T}^{\circ}$ under linear adjacency, even though it occupies a dedicated position in Spec, TP. ${ }^{28}$

$24 \quad$ Note that in this respect they agree with Poletto (2000), although their general analysis - as emphasized by the authors - is completely independent.

The authors discuss the structure in (32) at length, comparing it with parasitic plurals and the other phenomena they account for in the article. Since this kind of split never occurs in Campone, we refer the reader directly to Manzini \& Savoia's article. Note however that the structure in (32) predicts the completely unexpected order 'Subject clitic - Object clitic - subject clitic' to be completely normal, even though the presence of a part of the subject clitic below the object clitic is not attested in any other Romance variety (R. Kayne, p.c.). This hypothesis has been further elaborated by various scholars; see e.g. Uriagereka (1995), Belletti (2005) and most recently Arregi \& Nevins (2012). See e.g. Roberts 2010, who argues that subject clitics are internal merged to $\mathrm{T}^{\mathrm{min}}$ because they are defective heads. different types of clitics, unlike Poletto's (2000). 
In their analysis of the data of Forni di Sotto, the authors follow Halle \& Harris' (2005) analysis of metathesis and reduplication, arguing that the various orders found in this variety (30)-(31) are the result of a morphological metathesis rule. They agree with Manzini \& Savoia (2009) in assuming that the underlying forms of the subject clitic are $a l$, $a i$ and $a s$; in their account, these clitics are subject to a morphological rule of fission, which splits them into two separate forms: the higher [+/-third person] clitic and the lower $\varphi$-clitic. ${ }^{29}$

Since both parts of the subject clitic are moved to Spec,TP, they are higher than negation and object clitics: thus, the lower position of the second part of the subject clitic results from a rule of metathesis, which first copies the lower clitic below the negation (and optionally also below the object clitic), and then deletes the higher copy:
a. a 1 no du'ar $\quad(\rightarrow$ copying of the lower clitic $l)$
b. a $1 l_{1}$ no du'ar ( $\rightarrow$ movement of the copy to the right edge of the cluster)
c. a 1 no $l_{1}$ du'ar $(\rightarrow$ deletion of the higher copy of $l)$
d. a 1 no 1 du'ar (adapted from Calabrese \& Pescarini 2014: 304)

\section{The syntactic distribution of the clitic $a$ in the structure}

We now turn back to the variety of Campone. The description given in section 2 suggests that the clitic $a$ is a single clitic that realises the formal features of a functional head encoding the third person at PF. Within the cartographic framework, each syntactic position is specialised for a precise function, i.e. it has different semantic properties and can host a single element. Nevertheless, the exact position of $a$ in the syntactic structure is hard to define, since it could be located either under TP, or within the CP. We therefore apply a series of syntactic tests to establish its syntactic position. We follow the articulation of the $\mathrm{CP}$ ('Split-CP') proposed in Benincà \& Poletto (2004):

[Hang.Top [SceneSett. [LeftDisl. [ListInt. [ContrFoc1[ContrFoc2 [InformFoc] [IP

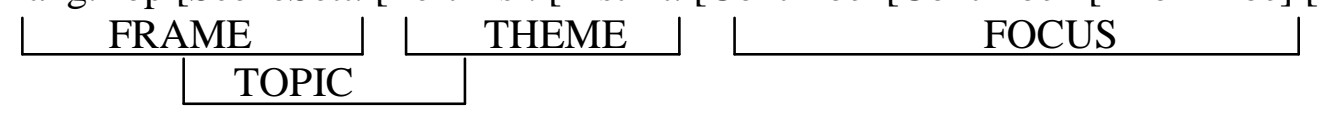

We will now attempt to locate the clitic $a$ following this hierarchy of positions.

\subsection{Syntactic tests to locate the subject clitic a within TP or CP}

To begin our analysis, we will firstly consider the position of the subject clitic $a$ with regard to other syntactic material in the $\mathrm{CP}$ and TP. We will proceed from top to bottom, considering the interaction of the clitic $a$ first with the higher and then with the lower elements occurring in the hierarchy given in (34). At the end

$29 \quad$ Calabrese \& Pescarini discuss also diachronic evidence in support of their analysis. Note that the authors do not exclude the possibility that forms like ' $a l$ ', ' $a s^{\prime}$ have been reanalysed as two completely separate clitics, probably by analogy with the second singular ' $i t u$ ', where the separation between the deictic and the TP-clitic is more clear-cut. 
of this section, it will be clear that $a$ is located at the CP/TP edge between $\mathrm{CP}$ and TP.

We thus start by analysing the position of $a$ in relation to elements occurring within the TOPIC field. First of all, the examples (35) show that $a$ is lower than subjects and topics. In (35), we observe that the clitic $a$ is lower than the lexical subject. In (35), instead, we show that the clitic $a$ is lower than clitic left dislocated elements:
a. La Delfina e la Maria a s van al mar the Delfina and the Maria $a$ SCL go to-the sea 'Delfina and Mary go to the sea'
b. Tranquillo, a la fin, a no l'è giut Tranquillo, finally, $a$ not SCL is gone 'Eventually, Tranquillo did not go (out)'
c. Il pan, a 1 mi lu compra lui the bread $a$ SCL to.me it buys he 'He will buy the bread for me'

In the FOCUS field, $a$ occurs in a lower position than contrastive Foci. Notice that in (36) the subject clitic $a l$ is used to double a contrastively focused subject (both lexical and pronominal):
a. IL PAN a l compra! THE BREAD $a$ SCL buys 'It is the bread that he is buying'
b. GIANNI a l'è giut dal miedi, no la Maria JOHN $a$ SCL is gone to.the doctor, not the Mary 'It is John who went to the doctor, not Mary'
c. Lui a 1 ha belghià manghiat, ma jè a no $\varnothing$ ha manghiat anco:ra he $a \mathrm{SCL}$ has already eaten, but she $a$ not SCL $(\varnothing)$ has eaten yet 'He has already eaten, while she has not eaten yet'

Another syntactic test to localise the clitic $a$ can be applied to contexts of $\mathrm{V}$-to-C movement, which we have partly discussed in our analysis of negative questions. If we consider the enclitics to be subject pronouns cliticised to the right of the verb (cf. Roberts $2010^{30}$ ), we must treat the clitic $a$ as lower than the finite verb both in yes/no questions (37) and in wh-questions which do not involve a complementiser (37). According to Poletto (2000), the finite verb raising to the $\mathrm{CP}$ in interrogatives targets a position that she defines as AgrCP, located under FOCUS:
a. Chiant-ai?
sing-ai
'Do they sing?'
$30 \quad$ Note that Roberts (2010) proposes that proclitics and enclitics have a different nature: the former are (defective) heads, while the latter are weak D-pronouns (and thus XPs). We do not address this possible difference here.



b. Plov-a?
rains- $a$
'Does it rain?'
c. Cui no ven-al?
who not come-al
'Who is not coming?'
d. Quan es-al partit?
when is-al left
'When did he leave?'
e. Parcé vai-al via?
why go-al away
'Why is he going away?'

The clitic $a$ is also located below the complementiser. This applies to both the high complementiser used in relative clauses and occurring in ForceP (38), and to the low complementiser in FinP (38) (cf. Rizzi 1997 and Poletto 2000: 128ff). Moreover, main wh-questions often include a complementiser, which blocks the raising of the finite verb to the $\mathrm{CP}$ (38). Notice that the extended form for the complementiser is chi, which mandatorily forms the cluster $c^{\prime} a$ when it is followed by $a$ in whatever context:

(38) a. Il fantat ch'a 1 ven doman a l'è il fì dala Mara the guy who $a$ SCL comes tomorrow $a$ SCL is the son of.the Mara 'The guy who will come tomorrow is Mara's son'

b. La Maria e la Leotina, ch'a s claman dutas las seras, a s son las sos amigas

the Mary and the Leontina who $a$ SCL call all the evenings $a$ SCL are the her friends

'Mary and Leontina, who call every evening, are her/his friends'

c. Crout ch'a no 1 partisi prima da las deis

I.believe that $a$ not SCL leave before of the ten

'I think that he will not leave before ten'

d. Giani $i_{i}$ a $l_{i}$ mi ha domandat quan ch'a $l_{j}$ è rivat John $a$ SCL to.me has asked when that $a$ SCL is arrived 'John ask me when he arrived'

e. Ce tantas caramelas ch'a i manghian? how much candy that $a$ SCL eat 'How much candy are they eating?'

In coordinated sentences, the subject clitic is repeated in each member of coordination: the clitic $a$ is thus lower than the coordination, and is strictly related to each finite verb involved in the coordination:

(39) a. Fedele a 1 cjanta cun te e a 1 bala cun jé Fedele $a$ SCL sings with you and $a$ SCL dances with her 'Fedele sings with you and dances with her' 
b. A i sunan e a i giujan a cjartas

$a$ SCL play and $a$ SCL play to cards

'They make music and they play cards'

The syntactic tests used in the course of the study (35)-(39) suggest that the clitic $a$ occupies a position lower than all the elements moved to or merged in the $\mathrm{CP}$.

We can now do further tests to examine the position of the subject clitic $a$ in relation to the elements that usually occur in the TP. In general, $a$ is located in a projection higher than the other elements in TP, such as low clitics and the finite verb.

Firstly, the clitic $a$ is higher than the second part of the subject clitic $l / \phi / i / s$ :

$$
\begin{aligned}
& \mathrm{Al} \quad / \mathrm{A} \varnothing \quad / \mathrm{Ai} / \mathrm{As} \text { ven } \\
& a \mathrm{SCL}_{\text {sg.m. }} \quad / a \mathrm{SCL}_{\text {sg.f. }} / a \mathrm{SCL}_{\text {pl.m. }} / a \mathrm{SCL}_{\text {pl.f. }} \text { comes/come }
\end{aligned}
$$

Secondly, it always appears on the left of dative clitics and object clitics: ${ }^{31}$

(41) a. Fedele a 1 mi dà chestu chi, a no 1 mi dà chel grand

Fedele $a$ SCL to.me gives this one, $a$ not SCL to.me gives that big

'Fedele gives me this one, he does not give me that big one'

b. A 1 ti vomp

$a$ SCL you see

'They see you'

To sum up, the canonical position of the lower subject clitic $l / \phi / i / s$ is to the right of the negation. In contrast, the clitic $a$ occurs in a position to its left without exception, and this holds in both referential and non referential contexts:

31 Note that in the variety of Campone the lower subject clitics $l / \phi / i / s$ are omitted when a third person object clitic is present:

(i) A no l'ha chiatat

$a$ not it has found

'He has not found it'

This fact has already been noted by Vanelli (1998: 108) for central Friulian, where the whole element $a l$ is omitted when it is followed by whatever clitic element, differently from Campone:

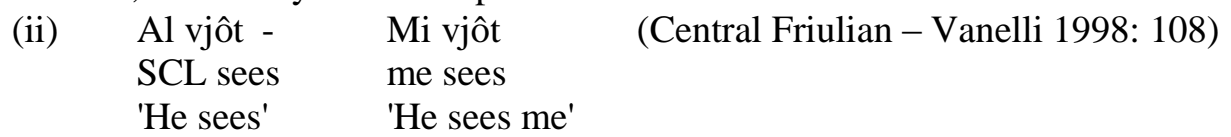

Finally, an idiosyncratic property of Camponese is that the co-occurrence of more than three clitics above the finite verb can (optionally) trigger movement of the lower part of the subject clitic in a position higher than the clitic negation no; we suggest interpreting this exceptional movement as a last resort operation:

(iii) A i no gli lu dan, tu vedarà!

$a$ SCL not to.him it gives, you will.see

'They certainly will not give it to him'

However, since the presence of object clitics has generally no effects on the clitic cluster $a l$ in Campone, we do not discuss the details of the object clitic syntax here. 

a. A no i manghiavan
$a$ not SCL ate
'They did not eat'
b. A no nevea
$a$ not snows
'It does not snow'

In conclusion, the clitic $a$ is lower than all of the following: the Topic Field, the projections intended for contrastive Focus in the Focus field, the finite verb raising to AgrCP in interrogative contexts, and the complementiser in FinP. It is, instead, higher than all other clitics: the subject clitics $l / \phi / i / s$, dative and accusative clitics, and the clitic negation no. Thus, the position of the clitic $a$ seems to be at the CP/TP edge.

The structure in (43) is a summary of the position of the subject clitic $a$ in relation to the other elements occurring within the $\mathrm{CP}$ and the TP:

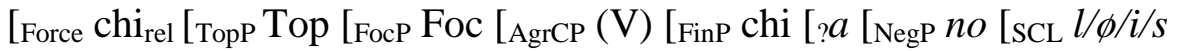

$$
\begin{aligned}
& \text { [clDat } \left.\left.\left.\left.\left.\left.\left.\left.\left.m i\left[\text { clAcc } l u\left[\mathrm{~T}^{\circ}(\mathrm{V}) \ldots \text { ] }\right]\right]\right]\right]\right]\right]\right]\right]\right]\right]\right]
\end{aligned}
$$

\section{Analysis of the subject clitic $a$ in Campone}

As we have seen in $\S 2.3$, the dialect of Campone differs from central Friulian varieties because the clitic $a$ can co-occur with negation and object clitics. Moreover, in this case there is no variation, since only one fixed order is possible:
a. A no 1 mi clame
$a$ not SCL me calls
'He doesn't call me'
b. $\quad *$ A (l) no mi (l) clame
$a$ (SCL) not me (SCL) calls

In (43), repeated here, we show that the relative order of subject clitics and other elements of the $\mathrm{CP}$ and TP is:

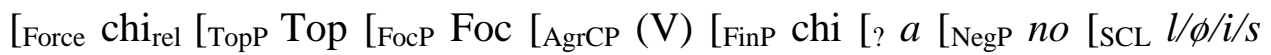

$$
\begin{aligned}
& \text { [clDat } \left.\left.\left.\left.\left.\left.\left.\left.\left.m i\left[\mathrm{clAcc} l u\left[\mathrm{~T}^{\circ}(\mathrm{V}) \ldots \text { ] }\right]\right]\right]\right]\right]\right]\right]\right]\right]\right]\right]
\end{aligned}
$$

We will now focus on the higher subject clitic $a$, since for the lower clitics $l / \phi / i / s$ Poletto's (2000) account of number and person clitics (29) seems perfectly compatible with the distribution and syntactic properties of these clitics in Campone. We suggest, however, that they be analysed as [u $\varphi$ ] (i.e., as agreement markers, Roberts 2010), adopting an idea already proposed by Benincà (1994b: 117 f.) for Friulian in general: ${ }^{32}$ since the lower clitics are always used when the

32 A general analysis of subject clitics as instantiations of AGR has already been done by Brandi \& Cordin (1981 and 1989) and Rizzi (1986). 
DP subject appears on the right of the verb (but only with definite subjects when the verb is unaccusative in Campone, see 0 and 0 in $\S 2.2$ ) and obligatorily double any type of subject (DPs, quantifiers, wh-moved subjects, cf. 0 and 0 ), she claims that they have been reanalysed as verbal inflections. ${ }^{33}$

In the next section, we argue that the forms $a l, a s, a i$ never form a single clitic in Campone; they are, in fact, a cluster of two different clitics. Consequently, the analyses proposed by Manzini \& Savoia (2009) and Calabrese \& Pescarini (2014) for Forni di Sotto cannot be extended to Campone ( $\$ 5.1)$. In $\S$ 5.2 we show that the clitic $a$ does not fit within Poletto's typology, since it displays a syntactically idiosyncratic behaviour. The section concludes by proposing that the clitic $a$ is located in SubjP (Rizzi \& Shlonsky 2007).

\subsection{The clitic a is a clitic on its own}

As we have seen, in Campone the relation between the higher clitic $a$ and the lower clitics $l / \phi / i / s$ is clear: they always form a cluster, except when a negation intervenes. When this occurs, the position of the negation between the two subject clitics clearly shows that they are located in two different projections. Another important property concerns the use of $a$ as an expletive pronoun ( $\$ 2.2)$, a usage also found in Forni di Sotto, but which has not been examined in Manzini \& Savoia (2009) and Calabrese \& Pescarini (2014) (we repeat here the relevant examples):
a. A nevea
$a$ snows
'It snows'
b. $\quad$ A son staz spinduz mà tanch bez $a$ are been spent a lot of money 'A lot of money has been spent'

Thus, a fundamental property of the clitic $a$ is that it always occurs when the verb is in the third person. We therefore follow Calabrese \& Pescarini (2014) and suggest that it bears a [+third person] feature, which must be realised through this clitic. ${ }^{34}$ However, we do not think that their morphological analysis can be extended to the Campone data.

While their approach may account for the diachronic development of subject clitics in Camponese, we cannot endorse it to explain the current situation. Leaving aside the question of whether a morphological approach is more suitable for the clitic split than a syntactic one, we are convinced that the necessary condition for postulating a (synchronic) metathesis rule is the optionality of the phenomenon, as is indeed the case in Forni di Sotto. In contrast, Campone

33 In this light, the position of low subject clitics on the right of object clitics in Forni di Sotto could be interpreted as strong evidence in favour of a reanalysis of these clitics as an element of verbal inflection. Thus, we could consider the variety of Forni as the most advanced stage in this process of reanalysis claimed by Benincà (1994b).

Recall that the only exception concerns the impersonal verb bisugna ('it is necessary'). 
displays no optionality at all, since the cluster $a$ no $l$ is mandatory. Hence, Calabrese \& Pescarini's hypothesis could explain the passage from a hypothetical original al no (if this was the correct form in the past in Camponese, too) to a no $l$. At a later stage, however, reanalysis must have occurred, as admitted by the authors themselves.

Consequently, the clitics we are now dealing with could be understood as having been shaped by a former metathesis rule (provided that Calabrese \& Pescarini's account about the diachronic role of metathesis is correct) ${ }^{35}$ which is, however, no longer operative in synchrony: were this rule still active, we would expect the 'displacement' to be optional, but this is never the case: ${ }^{36}$

$$
\begin{aligned}
& \text { a. } \quad * \text { A } 1 \text { no ven } \\
& \quad \text { a SCL not comes } \\
& \text { b. } \quad \text { A } 1 \text { no } 1 \text { ven } \\
& \quad a \text { SCL not SCL comes }
\end{aligned}
$$

(Campone)

On the other hand, for the Campone data we do not accept Manzini \& Savoia's (2009) analysis, either. Firstly because, like Calabrese \& Pescarini (2014), they assume that the underlying form is al. However, the data in (45) show that the order ' $a$ no $\mathrm{l} / \phi / \mathrm{i} / \mathrm{s}$ is fixed, and that $a l$ is not a single clitic in Campone - otherwise we would expect an alternation between $a$ no $l$ and $a l$ no, the latter instantiating the underlying form argued for in Manzini \& Savoia (2009). Even if there were an obligatory syntactic rule requiring the lower part of the subject to move rightward, i.e. under the clitic negation, the fact that the clitic $a$ (on its own) is independently attested (as expletive subject) suggests that $a l$ is always a cluster formed by two different clitics. The comparison between the contexts for expletive and referential subjects suggests that the clitic $a$ is merged independently of the cooccurrence of the lower clitic $l / \phi / i / s$. Hence, we claim that its function is always restricted to signalling the [+third person] feature exclusively, the $\varphi$-features being realised - when required - by the lower clitic. The clitic $a$ thus instantiates a single feature, while a clitic is usually defined as a bundle of features (see e.g. Roberts 2010). Further evidence supporting our approach is the parallelism with the second person $i$ tu in other varieties like Forni di Sotto and San Michele al

35 However, the hypothesis of Calabrese \& Pescarini faces some challenges in regard to diachronic evolution too: first, we must take into account the cases of the second person clitics $i$ tu of Forni di Sotto, which has probably never been a single clitic *itu. Moreover, for XVI century Pavano D'Onghia (2010) shows that the occurrences of $a+l$ in Ruzante have to be considered as a cluster of two separate clitics; thus, the single clitic al evolved only later, at least in pavano. Recall that the only exception to this rule is found when there is also an accusative clitic (fn. 31).

Note also that the variety of Clauzetto, which is geographically and linguistically closer to Campone than Forni di Sotto, has the alternation a no l/a l no, as in Forni:

(i) Lui a 1 no va/ Lui a no 1 va (Clauzetto; Brovedani 1980/81: 82). He $a$ SCL not goes / He $a$ not SCL goes 
Tagliamento (Benincà 1994b, Poletto 2000), which fully resembles $a l$ and is clearly a cluster of two separate clitics (see also fn. 35 ). ${ }^{37}$

There are, moreover, two theoretical reasons for rejecting Manzini \& Savoia's analysis. First, it is not clear why the only copy/displaced element is the $\varphi$-clitic, whereas the higher part $a$ is never found in Manzini \& Savoia's lower D position (32). This difference between $a$ and the lower clitic suggests that the former has to be treated as independent from the lower part, with separate syntactic properties and encoding its own syntactic information.

Secondly, even if we accept the idea that the underlying form of the clitic is al/ai/as, we have to posit a rightward movement of the second part of the clitic to under the position where the clitic negation is hosted. Since rightward movements are excluded by Kayne's (1994) LCA, we prefer an analysis in which the two subject clitics target two different projections independently, as suggested in Benincà (1994b) and largely in line with Poletto's (2000) subject clitic typology. $^{38}$

\subsection{The clitic a is located in SubjP}

Now, the question arises as to what type of clitic the $a$ of Campone is. Consider again Poletto's (2000) structure of subject clitics (29) and our relative order of the clitic $a$ with respect to other elements of the CP and the TP (43), repeated here:

[LDP inv $\mathrm{SCL}_{\mathrm{j}}\left[\mathrm{CPP}_{\mathrm{CP}}\right.$ deic SCL [FP $\mathrm{t}_{\mathrm{j}}$ [IP [NegP [NumbP $\mathrm{SCL}$ [HearerP $\mathrm{SCL}$ [SpeakerP inflV [TP]]]]]]]]] (Poletto 2000: 36)

$$
\begin{aligned}
& \text { [Force } \operatorname{chi}_{\text {rel }}\left[{ }_{\mathrm{TopP}} \text { Top }[\mathrm{FocP} \text { Foc }[\mathrm{AgrCP}(\mathrm{V})[\mathrm{FinP} \operatorname{chi}[?[a[\mathrm{NegP} n o\right. \\
& \left.\left.\left.\left.\left.\left.\left.\left[\mathrm{SCL} l / \phi / i / s\left[\mathrm{clDat} m i\left[\mathrm{clAcc} l u\left[\mathrm{~T}^{\circ}(\mathrm{V}) \ldots\right]\right]\right]\right]\right]\right]\right]\right]\right]\right]\right]
\end{aligned}
$$

When we compare the distribution of the clitic $a$ with Poletto's structure in (29), it is clear that, because it occurs higher than negation, any correspondence with her TP-clitics can immediately be excluded. On the other hand, it cannot be interpreted as an invariable clitic either, since it only occurs with the third person; moreover, the clitic $a$ is not necessarily in first sentence position, and, although it has no pragmatic value, it is obligatory whenever the verb is in the third person.

The deictic clitic seems to be the most suitable candidate for Campone's $a$. Deictic clitics have two forms, one for the first and second person, and another for the third person. Thus, their use is related to the same [+/-third person] feature that is borne by the clitic $a$ of Campone. Furthermore, the clitic forms a cluster with the complementiser, a fact held by Poletto (2000) to indicate its position within $\mathrm{CP}$ :

37 Remember however that in Campone the second person singular is just expressed with $t u$, because there is no clitic $i$.

In this respect, Manzini \& Savoia's account is not completely clear: on the one hand when they speak of the "copying" and "displacement" (Manzini \& Savoia 2009: 21, 22, 23) of the lower clitic to the right of the negation they seem to argue for a rightward movement; on the other, they consider the phenomena analysed to be caused by stranding (Manzini \& Savoia 2009: 23), which suggests that they are envisioning the leftward movement of the remnant part of the subject. 
(46) Las canajas ch'a s claman dutas las seras as son las sos amigas the girls that $a$ SCL call all the evenings $a$ SCL are the her friends 'The girls that call every evening are her friends'

However, the cluster does not seem necessarily related to strict adjacency in the structure: on the contrary, it seems to be possible for phonological reasons even when the complementiser and the clitic $a$ occupy two distant positions: the clitic $a$ clusters with the complementiser both when it is in the higher and in the lower position in the CP (usually associated with ForceP and FinP, cf. Rizzi 1997 and Poletto 2000: 128 f.). Furthermore, the fact that material can be inserted between the two elements shows that the clustering test does not establish the position of a clitic decisively, cf. (46) with (47):

(47) a. Ai saludat i fantaz chi doman a no i ven cun nos I.have greeted the boys that tomorrow $a$ not SCL come with us 'I have greeted the boys that aren't coming with us tomorrow'

b. Ai vidut la Leontina, chi anchia chist'an a no ha chiatat un fantat I.have seen the Leontina that also this year $a$ not $\operatorname{SCL}(\varnothing)$ has found a boyfriend 'I saw Leontina, who even this year hasn't found a boyfriend'

Notice that (47) is a restrictive relative clause, while (47) is appositive.

Furthermore, an important piece of data contradicts the analysis of $a$ as a deictic clitic: as Poletto (2000) points out, when there is V to C movement (first of all with interrogatives), the deictic clitic is either higher than the verb (48) or is not realised (49): ${ }^{39}$
a. A còmprin-u? (S. Michele al T., Friulian - Benincà 1994b: 122) $a$ they.buy-SCL
'Do they buy?'
b. Cui a compri-al il pan? who $a$ buys-SCL the breas
'Who buys the bread?'
(Ibid.)

c. Quant a van-u a Pordenon?

when $a$ go-SCL to Pordenone

'When are they going to Pordenone?'

(Poletto 2000: 59)

(49) Do (*a) van-u?

(Ibid.: 25)

where $a$ go-SCL

These data lead Poletto to propose the following structure for cases of $\mathrm{V}$ to C movement:

\footnotetext{
39 Poletto explains cases like (49) by arguing that some wh-pronouns (like $d o$, 'where', in the example) are in (or move to) a projection of CP lower than other wh-elements like quant ('when').
} 
[CP inv. SCL [CP deict. SCL [AgrCP $\left.\left.\mathrm{V}_{\mathrm{i}}+\mathrm{SCL}\left[\mathrm{NumbP}_{\mathrm{i}} \mathrm{tPersP}_{\mathrm{i}} \mathrm{t}_{\mathrm{C}}\right]\right]\right]$ (Poletto 2000: 52)

In (50), the invariable and deictic clitics are located above the finite verb, which targets AgrCP. ${ }^{40}$ Now, as we have seen in (37), the clitic $a$ of Campone appears in the enclitic position when the verb moves to $\mathrm{CP}:{ }^{41}$

\section{b. Plov-a? \\ rains- $a$ \\ 'Is it raining?'}

It is therefore necessary to postulate that a fifth type of clitic, located at the $\mathrm{CP} / \mathrm{TP}$ edge (lower than than Poletto's AgrCP and higher than NegP) be added to Poletto's typology. A first hypothesis could be that $a$ is located in FinP, as tentatively suggested by Roberts (2010: $237 \mathrm{n}$. 69) for the clitic $a$ of Gainago/Torrile (Aemilian). However, in this variety the clitic occurs with all persons (except for the third plural, where it has the form $i$ ) and does not seem to have a [+/-third person] feature. ${ }^{42}$

$40 \quad$ Note that the verb passes through NumbP and PersP when moving to CP. This prevents the TP-clitics from being realised. Poletto therefore claims that the enclitics that attach at the right edge of the verb in cases like (48) are not the same as the proclitics - as is demonstrated by various other data (see Poletto 2000: 52 ff.). Unlike their proclitic counterparts, the enclitics which move with the verb to AgrCP in (50) are "agreement morphemes that check their features in a projection located quite high in the structure, most probably within the $\mathrm{CP}$ domain" (Poletto 2000: 55). Roberts (2010) also considers enclitics and proclitics to be two different types of pronoun: proclitics are true clitic pronouns, while enclitics are weak D-pronouns. On the other hand, Cardinaletti \& Repetti (2008) claim that proclitic and enclitic pronouns are the same lexical items, differing only phonologically.

41 We exemplify this fact with the expletive $a$, since its distribution is straightforward - there is more variation when the subject is referential, cf. fn. 12 . In any case, the clitic $a$ never shows up on the left of the verb moved to C. Inversion of the clitic $a$ is also attested in Clauzetto, where, for independent reasons, it becomes $e$ in enclisis:
(i) Plovi-e?
(Brovedani 1981: 52)
rains-e
'Is it raining?'

In Gainago/Torrile, the behaviour of the clitic $a$ is similar to that in Campone, except for the fact that it occurs with the first five persons (unfortunately Roberts does not tell us if it appears as an enclitic in V to C movement). However, this is a fundamental difference, which leads us to think that in Gainago/Torrile this clitic is higher than in Campone, since it has neither [+/-third person] nor $\varphi$ features. If it really is in FinP in Gainago/Torrile, this would be another argument for our claim that the Camponese $a$ is in a lower position, i.e. in the highest portion of the TP (if we accept the idea that FinP is the lowest projection of CP). The clitic $a$ of Campone does not correspond to the homologous clitic $a$ of Bellinzonese either (Cattaneo 2009): Cattaneo shows that in this variety the clitic 
Thus, the most suitable position for the clitic $a$ of Campone seems to be a very high position of the TP, in particular SubjP (Rizzi \& Shlonsky 2007; see also Cardinaletti 2004 and Cognola 2013). In any case, we exclude its incorporation with the verb in $\mathrm{T}^{\circ}$, since the clitic $a$ and the verb are divided by at least one projection, i.e. $\mathrm{NegP}$.

Let us now consider whether the clitic $a$ is a head or a maximal projection (XP). There are some strong arguments for the latter: the obligatory use of the clitic $a$ as an expletive subject resembles languages like French or German, where all pronouns are either strong or weak (Cardinaletti \& Starke 1999), and thus maximal projections (XPs). Furthermore, the purely expletive nature of the clitic $a$ clearly results in cases of passivisation, where $a$ can co-occur with a verb with third plural morphology (51)-(52): ${ }^{43}$

(51) A son staz spinduz mà tanch bez

$a$ are been spent a lot of money

'A lot of money has been spent'

(52) A si sint a cjantà ucei in tal bosc

a si hears to sing birds in the wood

'One hears birds singing in that wood'

In the example (51) the clitic a precedes the passivised verb spindi ('spend'), while the subject DP is on the right edge of the sentence. Example (52), on the other hand, is an impersonal construction formed with the impersonal/mediopassive si (cf. Cinque 1988, D'Alessandro 2007, Roberts 2010: $120 \mathrm{ff}$ ). In such cases, the clitic $a$ would be a weak pronoun which may satisfy the EPP itself, being merged in Spec,SubjP. ${ }^{44}$ This would amount to saying that in Campone it is a phonological realisation of pro (which is located in Spec,SubjP according to Rizzi \& Shlonsky 2007). Moreover, this approach would prove the hypothesis that in Camponese, as in other NIDs, the subject DP always moves to CP (cf. fn. 20).

However, even though no argument is decisive, ${ }^{45}$ we prefer to consider the clitic $a$ as a head, thus adopting the general interpretation of clitics in NIDs (see

$a$ is located in the CP, and signals the transit of the lexical subject to a Leftperipheral position (like Topic or Focus). Taraldsen's $(2001,2002)$ analysis of the expletive clitic $i$ in Vallader, which the author compares with the French qui, analysed as 'que+Expl'. Rizzi \& Shlonsky (2007) update Taraldsen's proposal for French qui, analysing the $-i$ as a clitic-like element externally merged in Fin ${ }^{\circ}$. However, the French $-i$ is more like the clitic $a$ of Gainago/Torrile, because both are [ $\alpha$ Person] (i.e., they are insensitive to person distinctions). As regards the Vallader clitic $i$, unfortunately the data reported by Taraldsen are not sufficient to determin with which persons it can be used (all examples are in the third person). regards the pronouns that have $\varphi$-features (i.e., the lower subject clitics), the only 
e.g. Rizzi 1986, Brandi \& Cordin 1989, Poletto 2000, Roberts 2010). ${ }^{46}$ Moreover, if we compare the clitic $a$ with the French clitics, which are weak D-pronouns (and thus XPs), we notice that there are several crucial differences: the obligatory repetition of the clitic $a$ in coordination, its co-occurrence with lexical subjects and the absence of a full series of clitics for all persons are among the properties that clearly distinguish the clitic $a$ from French weak pronouns. The analogy with the other clitic pronouns of Campone, which are all heads, further strengthens our proposal.

We therefore propose interpreting the clitic $a$ as the spell-out of the functional head $\mathrm{Subj}^{\circ}$ proposed in Rizzi and Shlonsky (2007). In this case, this functional head encodes the [+/-third person] feature and the DP-subject (or pro) moves to Spec,SubjP to satisfy the EPP. This approach has the further advantage of treating all instances of $a$ in the same way, without distinguishing between the expletive and the referential.

\section{Conclusions}

Our analysis of the subject clitic $a$ in the variety of Campone has shown that it incompatible with Poletto's (2000) typology of subject clitics: our syntactic tests clearly demonstrated its idiosyncratic, unpredicted behaviour. We also compared the data of Campone with those of Forni di Sotto, in order to determine whether Manzini \& Savoia's (2009) or Calabrese \& Pescarini's (2014) analyses could be extended to Campone. Our findings demonstrate that a new approach is necessary, since neither account's key arguments can be transferred to Campone.

Following Poletto's proposal, and comparing the position of the clitic $a$ in relation to several elements that occur in the $\mathrm{CP}$ and in the higher part of the TP, we have suggested that the subject clitic $a$ is located in $\operatorname{Subj}^{\circ}$, in the highest projection of TP. This places the clitic at the leftmost edge of a real 'clitic field', which can be identified with the highest portion of the TP. The field also includes negation, the lower subject clitics (which bear the $\varphi$-features), and all the other clitics (direct and indirect objects, partitives and the impersonal/mediopassive $s i$ ).

Our proposal is fully compatible with Rizzi \& Shlonsky's (2007) hypothesis of the existence of a SubjP in the highest part of the TP. However, some of the data undoubtedly deserve further investigation: neither the XP or head nature of the clitic $a$, nor the analysis of negated $\mathrm{V}$ to $\mathrm{C}$ interrogatives is completely clear and both are still open questions.

\section{References}

Arregi, Karlos \& Nevins, Andrew. 2012. Morphotactics: Basque Auxiliaries and the Structure of Spellout. Dordrecht: Springer. http://dx.doi.org/10.1007/978-94-007-3889-8

ones which can incorporate into $\mathrm{T}^{\circ}$ - Poletto's CP clitics are (implicitly) excluded from this analysis, since they never incorporate to the verb. 
Belletti, Adriana. 2005. "Extended Doubling and the VP periphery". Probus, 17.1: $1-36$. http://dx.doi.org/10.1515/prbs.2005.17.1.1

Benincà, Paola. 1994a. "Il clitico $a$ nel dialetto padovano". In P. Benincà, $L a$ variazione sintattica. Studi di dialettologia romanza, 15-27. Bologna: Il Mulino (originally published in $\mathrm{P}$, Benincà et al. (eds.). 1984. Scritti Linguistici in Onore di Giovan Battista Pellegrini. Pisa: Pacini).

Benincà, Paola. 1994b. "Punti di sintassi comparata dei dialetti italiani settentrionali". In $\mathrm{P}$. Benincà, La variazione sintattica. Studi di dialettologia romanza, 105-138. Bologna: il Mulino, (originally published in: G. Holtus \& K. Ringger (eds.). 1986. Raetia antiqua et moderna. W. Th. Elwert zum 80. Geburtstag. Tübingen: Niemeyer).

Benincà, Paola. 2011. "Clitici e particelle nelle varietà provenzali". In J. Garzonio (ed.), Studi sui dialetti del Piemonte. Quaderni di lavoro ASIt 13, 1-33.

Benincà, Paola \& Poletto, Cecilia. 1994. "Bisogna and its Companions: the Verbs of Necessity". In G. Cinque et al. (eds.), Paths towards Universal Grammar. Studies in Honor of R. Kayne, 35-58. Washington, D.C., Georgetown University Press.

Benincà, Paola \& Poletto, Cecilia. 2004. "Topic, Focus and V2: Defining the CP sublayers". In L. Rizzi (ed.), The structure of $C P$ and IP, 52-75. Oxford: Oxford University Press.

Benincà, Paola \& Poletto, Cecilia. 2005. "The third dimension of person features". In L. Cornips \& K.P. Corrigan (eds.), Syntax and Variation. Reconciling the Biological and the Social, 265-299. Amsterdam/Philadelphia: John Benjamins. http://dx.doi.org/10.1075/cilt.265.15ben

Benincà, Paola, Renzi, Lorenzo \& Vanelli, Laura. 2007. "A typology of Romance subject pronouns". In I. Roberts (ed.), Comparative Grammar - v. 2. The null-subject parameter, 234-243. London: Routledge.

Brandi, Luciana \& Cordin, Patrizia. 1981. "Dialetti e italiano: un confronto sul parametro del soggetto nullo". Rivista di Grammatica generativa, 6: 3387.

Brandi, Luciana \& Cordin, Patrizia. 1989. "Two Italian dialects and the null subject parameter,". In O. Jaeggli \& K. Safir (eds.), The Null Subject Parameter, 111-142. Dordrecht: Kluwer. http://dx.doi.org/10.1007/978-94-009-2540-3_4

Brovedani, Loredana. 1980/81. La formazione delle frasi relative e interrogative nella varietà friulana di Clauzetto. MA thesis, Università di Padova.

Calabrese, Andrea \& Pescarini, Diego. 2014. "Clitic Metathesis in the Friulian Dialect of Forni di Sotto". Probus 26.2: 275-308.

Cardinaletti, Anna. 1990. Impersonal constructions and sentential arguments in German. Padova: Unipress.

Cardinaletti, Anna. 2004. "Toward a cartography of subject positions". In L. Rizzi (ed.), The Structure of $C P$ and IP. The Cartography of Syntactic Structures, 115-165. Oxford/New York: Oxford University Press.

Cardinaletti, Anna \& Repetti, Lori. 2008. "The Phonology and Syntax of Preverbal and Postverbal Subject Clitics in Northern Italian Dialects". Linguistic Inquiry 39.4: 523-563. 
http://dx.doi.org/10.1162/ling.2008.39.4.523

Cardinaletti, Anna \& Starke, Michael. 1999. "The typology of structural deficiency: A case study of three classes of pronouns". In H. van Riemsdijk (ed.), Clitics in the Languages of Europe, 145-233. Berlin: Mouton de Gruyter.

http://dx.doi.org/10.1515/9783110804010.145

Cattaneo, Andrea. 2009. It Is all about Clitics: The Case of a Northern Italian Dialect like Bellinzonese. PhD thesis, New York University.

Cinque, Guglielmo. 1988. "On si Constructions and the Theory of Arb". Linguistic Inquiry 19.4: 521- 583.

Cognola, Federica. 2013. Syntactic Variation and Verb Second. A German Dialect in Northern Italy. Amsterdam/Philadelphia: John Benjamins. http://dx.doi.org/10.1075/la.201

D'Alessandro, Roberta. 2007. Impersonal si constructions. Berlin/New York: Mouton de Gruyter.

http://dx.doi.org/10.1515/9783110207514

D'Onghia, Luca. 2010. "Sulla sintassi del clitico a" nella documentazione padovana (secc. XV-XVII)". In G. Ruffino \& M. D'Agostino (eds.), Storia della lingua italiana e dialettologia, 393-415. Palermo: Centro di studi filologici e linguistici siciliani.

Frau, Giovanni. 1984. Friuli (Profilo dei dialetti italiani 6). Pisa: Pacini.

Halle, Morris \& Harris, James. 2005. "Unexpected plural inflections in Spanish: Reduplication and Metathesis". Linguistic Inquiry 36: 195-222. http://dx.doi.org/10.1162/0024389053710710

Halle, Morris \& Marantz, Alec. 1993. "Distributed morphology and the pieces of inflection". In: K. Hale \& S.J. Keyser (eds.), The view from Building 20, 111-176. Cambridge, MA: MIT Press.

Halle, Morris \& Marantz, Alec. 1994. "Some Key Features of Distributed Morphology". In A. Carnie, et al. (eds.), Papers on Phonology and Morphology. MIT Working Papers in Linguistics 21: 275-88.

Harley, Heidi \& Ritter, Elizabeth. 2002. "Person and Number in Pronouns: A Feature-Geometric Analysis". Language 78.3: 482-526. http://dx.doi.org/10.1353/lan.2002.0158

Holmberg, Anders \& Roberts, Ian. 2010. "Introduction: Parameters in Minimalist Theory". In: T. Biberauer, et al. (eds.), Parametric Variation: Null Subjects in Minimalist Theory, 1-57. Cambridge: Cambridge University Press. http://dx.doi.org/10.1017/cbo9780511770784.001

Kayne, Richard. 1994. The Antisymmetry of Syntax. Cambridge, MA: MIT Press.

Manzini, Maria Rita. 2008. "Doubling by clitics and doubling of clitics: The case of negation". In S. Barbiers (ed.), Syntactic Doubling in European Dialects (Syntax and Semantics), 69-102. Amsterdam: Emerald Group Publishers. http://dx.doi.org/10.1163/9781848550216_004

Manzini, Maria Rita \& Savoia, Leonardo M. 2005. I dialetti italiani e romanci. Morfosintassi generativa. 3 Vols. Alessandria: Edizioni dell'Orso.

Manzini, Maria Rita \& Savoia, Leonardo M. 2007. A unification of morphology and syntax. Studies in Romance and Albanian varieties. London: Routledge. 
Manzini, Maria Rita \& Savoia, Leonardo M. 2008. "Uninterpretable features are incompatible in morphology with other minimalist postulates". In R. Freidin, et al. (eds.), Foundational Issues in Linguistic Theory, 43-72. Cambridge, MA: MIT Press. http://dx.doi.org/10.7551/mitpress/9780262062787.003.0004

Manzini, Maria Rita \& Savoia, Leonardo 2009. "Morphology dissolves into syntax: Infixation and Doubling in Romance languages". Annali Online di Ferrara-Lettere 1: 1-28.

Marantz, Alec. 1988. "Clitics, morphological merger, and the mapping to phonological structure". In M. Hammond \& M. Noonan (eds.), Theoretical Morphology: Approaches in Modern Linguistics, 253-270. San Diego: Academic Press.

Poletto, Cecilia. 2000. The Higher Functional Field. Oxford: Oxford University Press.

Renzi, Lorenzo \& Vanelli, Laura. 1983. "I pronomi soggetto in alcune varietà romanze". In P. Benincà et al. (eds.), Scritti linguistici in onore di G.B. Pellegrini, 121-145. Pisa: Pacini.

Rizzi, Luigi. 1986. "On the status of subject clitics in Romance". In O. Jaeggli \& C. Silva Corvalan (eds.), Studies in Romance Linguistics, 137-52. Dordrecht: Foris.

Rizzi, Luigi. 1997. "The fine structure of the left periphery". In L. Haegeman (ed.), Elements of grammar, 281-337. Dordrecht: Kluwer. http://dx.doi.org/10.1007/978-94-011-5420-8_7

Rizzi, Luigi \& Shlonsky, Ur. 2007. "Strategies for subject extraction". In U. Sauerland \& H.-M. Gärtner (eds.), Interfaces + recursion = language? ; Chomsky's minimalism and the view from syntax-semantics, 115-160. Berlin: Mouton de Gruyter. http://dx.doi.org/10.1515/9783110207552

Roberts, Ian. 2010. Agreement and Head Movement: Clitics, Incorporation, and Defective Goals. Cambridge, MA/London: MIT Press http://dx.doi.org/10.7551/mitpress/9780262014304.001.0001

Taraldsen, Knut T. 2001. "Subject extraction, the distribution of expletives and stylistic inversion". In A. Hulk, \& J.-Y. Pollock (eds.), Subject inversion in Romance and the theory of universal grammar, 163-182. New York: Oxford University Press.

Taraldsen, Knut T. 2002. "The Que/Qui Alternation and the Distribution of Expletives". In P. Svenonius (ed.), Subjects, Expletives and the EPP, 2942. New York/Oxford: Oxford University Press.

Tomaselli, A. 1990. "COMP as a Licensing Head: An Argument Based on Cliticization". In J. Mascaró \& M. Nespor (eds.) Grammar in Progress: GLOW Essays for Henk van Riemsdijk, 433-445. Dordrecht: Foris. http://dx.doi.org/10.1515/9783110867848.433

Torrego, Esther. 1992. "Case and agreement structure". Ms., University of Massachusetts.

Uriagereka, Juan. 1995. "Aspects of Clitic Placement in Western Romance". Linguistic Inquiry 26.1: 79-123.

Vanelli, Laura. 1987. "I pronomi soggetto nei dialetti italiani settentrionali dal Medio Evo ad oggi". Medioevo Romanzo 12: 173-211. 
Vanelli, Laura. 1998. I dialetti italiani settentrionali nel panorama romanzo. Studi di sintassi e morfologia. Roma: Bulzoni. 